\title{
CO adsorption and dissociation on iron oxide supported Pt particles.
}

\author{
Y.-N. Sun, Z-H. Qin, M. Lewandowski, S. Shaikhutdinov*, H.-J. Freund \\ Abteilung Chemische Physik, Fritz-Haber-Institut der Max-Planck-Gesellschaft, \\ Faradayweg 4-6, Berlin 14195
}

\begin{abstract}
We studied CO adsorption on Pt particles deposited on well-ordered $\mathrm{Fe}_{3} \mathrm{O}_{4}(111)$ thin films grown on $\mathrm{Pt}(111)$ by temperature programmed desorption (TPD). A highly stepped $\operatorname{Pt}(111)$ surface produced by ion sputtering and annealing at $600 \mathrm{~K}$ was studied for comparison. Structural characterization was performed by scanning tunneling microscopy and Auger electron spectroscopy. The TPD spectra revealed that in addition to the desorption peaks at $\sim 400$ and $\sim 480 \mathrm{~K}$, assigned to $\mathrm{CO}$ adsorbed on $\mathrm{Pt}(111)$ facets and low -coordination sites respectively, the Pt nanoparticles annealed at $600 \mathrm{~K}$ exhibit a desorption state at $\sim 270 \mathrm{~K}$. This state is assigned to initial stages of strong metal-support interaction resulting in partial Fe-Pt intermixing. On both $\mathrm{Pt} / \mathrm{Fe}_{3} \mathrm{O}_{4}(111)$ and stepped $\mathrm{Pt}(111)$ surfaces $\mathrm{CO}$ is found to dissociate at $500 \mathrm{~K}$. The results suggest that $\mathrm{CO}$ dissociation and carbon accumulation occur on the low-coordinated Pt sites.
\end{abstract}

Keywords: Platinum; Iron oxides; $\mathrm{CO}$ adsorption; $\mathrm{CO}$ dissociation; Strong metal support interaction

* Corresponding author: shamil@ fhi-berlin.mpg.de 


\section{Introduction.}

Adsorption of carbon monoxide on platinum surfaces is one of the most explored reactions in surface science (e.g., see [1]). Numerous studies performed on clean Pt single crystal surfaces showed that CO preferentially occupies atop sites on Pt surfaces and also bridge sites at increasing coverage. The binding energy of $\mathrm{CO}$ depends on the $\mathrm{Pt}$ surface structure. From surfaces with the low Miller indices CO desorbs in a relatively broad signal, between $300 \mathrm{~K}$ and $550 \mathrm{~K}$, in temperature programmed desorption (TPD) spectra [2-6]. Stepped and kinked Pt surfaces typically exhibit two distinct desorption states, i.e. at $\sim 400$ and $\sim 500 \mathrm{~K}[6-8]$, which have been assigned to the (111)-like terraces and low -coordination sites, respectively. A similar assignment was applied for supported Pt particles [9-12]. For example, Pt particles, deposited at low coverage both on amorphous alumina and $\alpha-\mathrm{Al}_{2} \mathrm{O}_{3}(0001)$ supports at $300 \mathrm{~K}$, showed a single desorption peak at $\sim 510 \mathrm{~K}$, while the larger aggregates revealed an additional desorption state at $\sim 400 \mathrm{~K}[9,10]$.

It was generally believed that $\mathrm{Pt}$ does not appreciably dissociate $\mathrm{CO}$, although controversial results were reported [5-8, 13-16]. Somorjai and co-workers first showed that $\mathrm{CO}$ dissociation on $\mathrm{Pt}$ is, in fact, a surface structure sensitive reaction [13]. Using x-ray photoelectron spectroscopy, they observed carbon deposition upon $\mathrm{CO}$ adsorption on the $\mathrm{Pt}(\mathrm{s})-6(111) \times(710)$ surface. The Pt atoms at steps and kinks were assigned to the sites for CO dissociation. Using field emission microscopy for a Pt single crystal rod, Li et al. [15] also showed that the kinked areas facilitate CO dissociation. The latter was clearly observed at elevated CO pressures. Using sum frequency generation spectroscopy at 40 Torr of CO and Auger electron spectroscopy (AES) McCrea et al. showed that CO dissociation occurs on $\operatorname{Pt}(111), \operatorname{Pt}(557)$ and $\operatorname{Pt}(100)$ at 673, 548 and $500 \mathrm{~K}$, respectively [17]. The authors suggested that dissociation proceeds via CO-induced surface roughening at high pressures and temperatures, but this mechanism was revisited in the more recent work by Rupprechter et al. [16].

When supported on reducible transition metal oxides such as $\mathrm{CeO}_{2}$ and $\mathrm{TiO}_{2}, \mathrm{Pt}$ particles exhibit a so-called strong metal support interaction (SMSI) $[11,18,19]$ resulting in a dramatic decrease of CO uptake due to particles' encapsulation by the reduced oxide support 
at elevated temperatures (typically, above $700 \mathrm{~K}$ ). We have recently demonstrated that $\mathrm{Pt}$ particles supported on well-ordered iron oxide $\mathrm{Fe}_{3} \mathrm{O}_{4}(111)$ films also undergo the SMSI effect via encapsulation [20, 21]. Scanning tunneling microscopy (STM) studies showed that the top facets of the Pt particles annealed at temperatures above $800 \mathrm{~K}$ exhibit the structure of a $\mathrm{FeO}(111)$ film grown on $\mathrm{Pt}(111)$.

In this work, we studied $\mathrm{CO}$ adsorption on Pt particles supported on $\mathrm{Fe}_{3} \mathrm{O}_{4}(111)$ by TPD, AES, and STM. Perfect and highly stepped Pt(111) surfaces were used as reference materials. The results indicate that vacuum annealing at $600 \mathrm{~K}$, i.e. before the $\mathrm{FeO}$ overgrowth has been observed, causes Fe migration on/into the Pt particles as the initial stage of the SMSI. On both $\mathrm{Pt} / \mathrm{Fe}_{3} \mathrm{O}_{4}(111)$ and stepped $\mathrm{Pt}(111)$ surfaces $\mathrm{CO}$ is found to dissociate at $500 \mathrm{~K}$ resulting in carbon deposition. The TPD results suggest that CO dissociation and carbon accumulation occur on the low-coordinated Pt sites.

\section{Experimental}

The experiments were performed in two UHV chambers (TPD and STM, base pressure below $3 \times 10^{-10}$ mbar) equipped with a low energy electron diffraction/Auger electron spectroscopy setup (LEED/AES, from Specs), and a quadrupole mass spectrometer (QMS, Hiden HAL 301). In the TPD chamber the Pt (111) crystal ( $10 \mathrm{~mm}$ in diameter, $1.5 \mathrm{~mm}$ in thickness, from Mateck) was spot-welded to two parallel Ta wires used for resistive heating and also for cooling by filling a manipulator rod with liquid nitrogen. The temperature was measured by a chromel-alumel thermocouple spot-welded to the backside of the crystal.

In the STM chamber the Pt(111) crystal, mounted to a Pt sample holder, was heated by electron bombardment from the backside. The temperature was controlled using a chromelalumel thermocouple spot-welded to the edge of the crystal. In both chambers the crystal temperature was controlled using a feedback control system (Schlichting Phys. Instrum.).

The preparation of thin $\mathrm{Fe}_{3} \mathrm{O}_{4}(111)$ films on $\mathrm{Pt}(111)$ is described elsewhere [22,23]. Briefly, one monolayer (ML) of Fe is deposited onto clean $\mathrm{Pt}(111)$ at $300 \mathrm{~K}$ and subsequently annealed in $10^{-6}$ mbar $\mathrm{O}_{2}$ at $1000 \mathrm{~K}$ for $2 \mathrm{~min}$ to form a $\mathrm{FeO}(111)$ monolayer film. Repeated 
cycles of $5 \mathrm{ML} \mathrm{Fe}$ deposition and oxidation results in $\mathrm{Fe}_{3} \mathrm{O}_{4}(111)$ films as judged by LEED and STM. The average thickness of the films used in this work is about $10 \mathrm{~nm}$.

Iron and Pt (both 99.95\%, Goodfellow) were deposited using electron beam assisted evaporators (Focus EFM3). During deposition, the sample was biased with a retarding potential to prevent metal ions from being accelerated towards the sample. Calibration of $\mathrm{Pt}$ deposition rate in the TPD chamber was performed with a quartz microbalance.

\section{Results and discussion}

Figures 1(a,b) show typical large-scale STM images of $\mathrm{Pt} / \mathrm{Fe}_{3} \mathrm{O}_{4}(111)$ surfaces that were annealed in UHV at $600 \mathrm{~K}$ for $5 \mathrm{~min}$. The vacuum annealing was performed in order to eliminate structural changes during CO TPD experiments. At sub-monolayer coverage Pt forms two-dimensional islands, while large, well-faceted Pt particles are formed at higher coverage. Although atomic resolution was not achieved on Pt deposits (but on bare support, see $[20,21])$, it is conceivable that $\mathrm{Pt}$ particles grow on a $\mathrm{Fe}_{3} \mathrm{O}_{4}(111)$ film via the same epitaxial relationships as between the film and the $\operatorname{Pt}(111)$ substrate underneath. The height of the particles seen in Fig. 1a is about $0.5 \mathrm{~nm}$, on average, that roughly corresponds to 2 layers of $\mathrm{Pt}(111)$. At high coverages the particles grow both in lateral size and height (up to $\sim 1 \mathrm{~nm}$ ) while exposing atomically flat $\mathrm{Pt}(111)$ top facets as shown in Fig. $1 b$.

Figure 2a shows CO TPD spectra of a $\mathrm{Pt} / \mathrm{Fe}_{3} \mathrm{O}_{4}(111)$ surface annealed to $600 \mathrm{~K}$ as a function of Pt coverage. The low temperature signals, i.e., below $200 \mathrm{~K}$, were observed on the pristine films prior to Pt deposition (not shown here). The highest de sorption state, found for the clean films, i.e. at $\sim 230 \mathrm{~K}$ (see also [24]), has been associated with defects sites, which are now decorated by $\mathrm{Pt}$ and are, therefore, not visible in the spectra presented. Thus, three desorption peaks, centered at 270, 400 and $480 \mathrm{~K}$, with the coverage-dependent intensity ratios are related to $\mathrm{Pt}$ particles. The latter peak is more pronounced at the low Pt coverage, whereas the signals at 400 and $270 \mathrm{~K}$ gain intensity with increasing coverage.

On the basis of the literature results [9-12], the desorption states at 400 and $480 \mathrm{~K}$ can be explained in terms of $\mathrm{CO}$ adsorbed on $\mathrm{Pt}(111)$ facets and low-coordination sites, respectively. To validate this assignment, Fig. $2 b$ depicts a TPD spectrum of CO obtained on 
the $\mathrm{Pt}(111)$ surface produced by $1 \mathrm{keV} \mathrm{Ar}^{+}$ion sputtering at $300 \mathrm{~K}$ and subsequent annealing at $600 \mathrm{~K}$ for $5 \mathrm{~min}$. This treatment yields a rough surface with a small width of $\operatorname{Pt}(111)$ terraces and a high density of low-coordination sites (step edges and kinks), as illustrated by the STM image in Fig. 1c (see also [25]). Besides the main TPD signal from the Pt(111) surface (centered at $400 \mathrm{~K}$ ), an additional peak at $\sim 510 \mathrm{~K}$ is clearly seen, that is assigned to $\mathrm{CO}$ adsorption on the low-coordinated $\mathrm{Pt}$ atoms. The absence of the $270 \mathrm{~K}$ state on the roughened $\mathrm{Pt}(111)$ surface indicates that this state is intrinsic to the $\mathrm{Pt} / \mathrm{Fe}_{3} \mathrm{O}_{4}(111)$ surface.

One could, in principle, associate this feature with other than (111) facets, constituting a particle surface, such as (100) and, to a lesser extent, (110) [26]. However, to the best of our knowledge, these two surfaces do not exhibit such a low temperature desorption peak [27-31]. In fact, the $\operatorname{Pt}(100)$ surface exhibits a desorption peak at higher temperature than that of $\mathrm{Pt}(111)$. Finite size effects are unlikely, too: The particles contain hundreds of Pt atoms, on average, and showed almost bulk behaviour in x-ray photoelectron spectra (not shown). If the $270 \mathrm{~K}$ state were the metal/oxide interfacial sites, one would expect to have more of these sites at low Pt coverage where the particles are smaller and the density is higher (see Fig. 1). In fact, Fig. 2a shows that the intensity of the $270 \mathrm{~K}$ signal scales with Pt coverage. Bearing in mind that $\mathrm{Pt}$ is prone to the SMSI effect with transition metal oxides via encapsulation at elevated temperatures, in particular occurring on the $\mathrm{Fe}_{3} \mathrm{O}_{4}(111)$ films at $\sim 800 \mathrm{~K}[20,21]$, we have tentatively linked the $270 \mathrm{~K}$ signal to the initial stages of SMSI effects. This interaction could, in principle, result in the support material $(\mathrm{Fe}, \mathrm{O})$ migration onto the Pt particles at $600 \mathrm{~K}$.

An O spillover onto Pt seems to be hardly possible since the affinity of $\mathrm{Pt}$ for oxygen is obviously lower than that of Fe. Therefore, we first address Fe migration onto Pt. To examine this hypothesis, we studied CO adsorption on 0.1 ML Fe deposited onto the stepped $\mathrm{Pt}(111)$ surface at $300 \mathrm{~K}$ and subsequently annealed in UHV at $600 \mathrm{~K}$ for $5 \mathrm{~min}$, i.e. as in the case of $\mathrm{Pt} / \mathrm{Fe}_{3} \mathrm{O}_{4}$. For this low $\mathrm{Fe}$ coverage one would expect Fe decorating the step edges. However, according to infrared studies [32] and Monte-Carlo simulations [33], the Fe atoms may also migrate into the sub-surface region of $\mathrm{Pt}$ at temperatures above $\sim 450 \mathrm{~K}$. Nonetheless, Figure $2 \mathrm{~b}$ shows that the intensity of the high temperature peak $(\sim 510 \mathrm{~K})$ on the $\mathrm{Fe} / \mathrm{Pt}(111)$ surface is reduced by a factor of 2 , while the CO capacity of the (111) terraces is almost unchanged. Interestingly, the new $\mathrm{CO}$ desorption state emerges below $300 \mathrm{~K}$, i.e. very similar to that 
observed on the $\mathrm{Pt} / \mathrm{Fe}_{3} \mathrm{O}_{4}$ surface (see Fig. 2a). Weakening of the $\mathrm{CO}$ bond on Pt-Fe surfaces has previously been reported for the Pt-terminated $\mathrm{Pt}_{80} \mathrm{Fe}_{20}(111)-(2 \times 2)$ surface, where a main desorption peak is observed at $\sim 340 \mathrm{~K}$ [34]. The similar downshift of $\mathrm{CO}$ desorption by surface alloying with other metals has also been reported, e.g. on Pt-Sn [35] and Pt-Ce [36] surfaces. Therefore, the results indicate that the 270 peak observed on the Pt particles originates from $\mathrm{Fe}$ migration onto the $\mathrm{Pt}$ particles or partial $\mathrm{Pt}-\mathrm{Fe}$ intermixing upon heating to elevated temperatures.

Figure 3 shows TPD results for $\mathrm{CO}$ adsorbed on $1.7 \mathrm{ML} \mathrm{Pt} / \mathrm{Fe}_{3} \mathrm{O}_{4}(111)$ at $100 \mathrm{~K}$, where also the $\mathrm{CO}_{2}$ signal (44 amu) was monitored. Two $\mathrm{CO}_{2}$ desorption peaks are observed at $\sim 150$ and $\sim 500 \mathrm{~K}$, which are definitely not due to $\mathrm{CO}$ cracking in the mass-spectrometer. The signal at $150 \mathrm{~K}$ has been detected on pristine $\mathrm{Fe}_{3} \mathrm{O}_{4}(111)$ films and thus assigned to $\mathrm{CO}_{2}$ adsorption on the oxide surface from the vacuum background upon cooling the sample to 100 $\mathrm{K}$. The experiments with $\mathrm{CO}$ on $\mathrm{O}$ precovered $\mathrm{Pt}(111)$ revealed $\mathrm{CO}_{2}$ formation in a broad peak between 300 and $400 \mathrm{~K}$ (not shown), which is missing in these spectra. Although there is some $\mathrm{CO}_{2}$ intensity at around 200 and $300 \mathrm{~K}$, which could, in principle, be assigned to $\mathrm{CO}+\mathrm{O}$ reaction on $\operatorname{Pt}(100)$ facets [31], the signal does not change upon repeating the spectra and most likely originates from the heating wires, etc. and thus can be neglected. Therefore, the results show no evidence for $\mathrm{O}$ spillover onto Pt particles.

The most prominent signal at $\sim 500 \mathrm{~K}$ must be attributed to the reaction limited desorption of $\mathrm{CO}_{2}$ that forms on the $\mathrm{Pt} / \mathrm{Fe}_{3} \mathrm{O}_{4}(111)$ interface. The isotopic experiments with $\mathrm{C}^{18} \mathrm{O}$ revealed that the $\mathrm{O}$ atoms for this reaction come from the iron oxide film as solely the formation of $\mathrm{C}^{16} \mathrm{O}^{18} \mathrm{O}$ was observed on the $\mathrm{Pt} / \mathrm{Fe}_{3}{ }^{16} \mathrm{O}_{4}(111)$ surface. Since $\mathrm{CO}$ on the (111) facets desorbs at much lower temperatures, $\mathrm{CO}_{2}$ can only be formed from $\mathrm{CO}$ more strongly bound to the sites that are interfacial in nature. This finding further supports the conclusion that the $270 \mathrm{~K}$ state cannot be assigned to the metal/oxide interface. In addition, the results show that $\mathrm{CO}$ on the interface sites desorbs at the same temperature (i.e., $480 \mathrm{~K}$ ) as for other low-coordination sites such as edges and corners.

Figure 3 shows that the $\mathrm{CO}_{2}$ production at $500 \mathrm{~K}$ gradually decreases in repeated $\mathrm{CO}$ TPD runs, indicating that oxygen reacted with $\mathrm{CO}$ cannot be replenished under these conditions. Interestingly, the high temperature CO peak also loses intensity. In fact, the $\mathrm{CO}$ 
capacity for this state is reduced even more if one takes into account the amounts of $\mathrm{CO}$ that is not desorbed, but consumed to form $\mathrm{CO}_{2}$ in the previous runs. In principle, this effect could be explained by CO-induced surface restructuring (note, that the surface has been annealed for 5 min at $600 \mathrm{~K}$ in UHV prior to TPD studies), site blocking by carbon deposition through CO dissociation (note, however, that the above isotopic experiments showed the Boudouard reaction $\left(2 \mathrm{CO}^{18} \rightarrow \mathrm{CO}_{2}{ }^{18}+\mathrm{C}\right)$ to be unfavorable), or both. The effects are expected to manifest the mselves more strongly at high $\mathrm{CO}$ exposures.

Figure 4a shows CO TPD spectra for $1.7 \mathrm{ML} \mathrm{Pt/Fe}{ }_{3} \mathrm{O}_{4}$ pre-exposed to $1500 \mathrm{~L} \mathrm{CO}(\sim$ $10^{-6} \mathrm{mbar}, 30 \mathrm{~min}$ ) first at 450 and then at $500 \mathrm{~K}$ It is clear that $\mathrm{CO}$ exposure at $450 \mathrm{~K}$ essentially causes no change, whereas the exposure at $500 \mathrm{~K}$ (i) strongly reduces $\mathrm{CO}$ desorption from the high temperature state (i.e., $480 \mathrm{~K}$ ); (ii) does not appreciably change CO capacity on $\operatorname{Pt}(111)$ terrace sites (at $~ 400 \mathrm{~K}$ ); and (iii) increases the signal at $100-300 \mathrm{~K}$ overlapping with the signal from the support. Very similar results are observed for highly stepped $\operatorname{Pt}(111)$ as shown in Fig. 4b. Also for the 0.1 ML Fe/Pt(111)s surface, the CO exposure at $500 \mathrm{~K}$ further reduces the signal at $\sim 500 \mathrm{~K}$ and increases the intensity of the low-temperature shoulder due to carbon deposition (see Fig. 4c). AES analysis revealed carbon formation after experiments at $500 \mathrm{~K}$ (see the insets). Meanwhile, the same treatment, applied to the perfect Pt(111) surface, showed no carbon signal in Auger spectra and no changes in CO TPD (not shown).

Therefore, the results suggest that it is not the Fe-Pt intermixing within the supported $\mathrm{Pt}$ particles that is responsible for the $\mathrm{CO}$ dissociation at $500 \mathrm{~K}$. In fact, the effect on $\mathrm{Fe} / \mathrm{Pt}(111)_{\mathrm{S}}$ is less pronounced than on the clean $\mathrm{Pt}(111)_{\mathrm{S}}$ surface $(c f$ Figs. $4 \mathrm{~b}$ and $4 \mathrm{c})$, most likely due to Fe decorating the low-coordinated Pt surface atoms on which $\mathrm{CO}$ dissociation occurs. Indeed, both at 450 and $500 \mathrm{~K}$, the (111) terraces are virtually clean in the $10^{-6}$ mbar $\mathrm{CO}$ pressure used in these experiments, while $\mathrm{CO}$ has sufficient residence time on the low coordination sites to dissociate before desorption. Apparently, the activation energy for $\mathrm{CO}$ dissociation is comparable with CO desorption energy on these sites, i.e. about $130 \mathrm{~kJ} / \mathrm{mol}$ calculated using the Redhead formula [37] and a frequency pre-factor $10^{13} \mathrm{~s}^{-1}$. The carbon left by $\mathrm{CO}$ dissociation accumulates on the $\mathrm{Pt}$ low-coordinated sites and thus suppresses $\mathrm{CO}$ desorption from the high temperature state, i.e. at $480-500 \mathrm{~K}$. 
In order to determine whether $\mathrm{CO}$ dissociation depends on the Pt particle size, the experiments were performed for different Pt coverages as shown in Fig. 5. For all samples, high $\mathrm{CO}$ exposure at $500 \mathrm{~K}$ resulted in carbon deposition as shown in the AES spectra presented in the ins ets. Concomitantly, the $480 \mathrm{~K}$ peak is strongly reduced, in particular for the highest Pt coverage studied, while a broad desorption signal at temperatures below $300 \mathrm{~K}$ gains intensity and overlaps with the signal of the bare support. (Note that the same exposure to pure $\mathrm{Fe}_{3} \mathrm{O}_{4}(111)$ films did not result in new $\mathrm{CO}$ desorption states and carbon deposition).

The carbon deposits can be removed by reaction with $10^{-6} \mathrm{mbar}_{2}$ at $500 \mathrm{~K}$. The chemisorbed oxygen left on the Pt surface is in turn removed by $\mathrm{CO}$ at $450 \mathrm{~K}$, i.e., at the temperature when no $\mathrm{CO}$ dissociation occurs (see Fig. 4). This procedure is similar to that previously used for the $\mathrm{Pd} / \mathrm{Al}_{2} \mathrm{O}_{3} / \mathrm{NiAl}(110)$ system [38, 39], and practically recovers the original CO TPD spectra and cleanliness of the Pt surfaces as judged by AES.

The results, presented in Figs. 4 and 5, show that the CO capacity for the (111) terrace sites is least affected by carbon deposition (as more clearly observed on the stepped $\operatorname{Pt}(111)$ surface). Therefore, it is plausible that carbon blocks the low-coordinated Pt sites and thus weakens $\mathrm{CO}$ bonding to the adjacent terrace sites, ultimately resulting in the low-temperature desorption state below $300 \mathrm{~K}$. Similar changes are observed in experiments with Fe deposition onto the stepped $\mathrm{Pt}(111)$ surface (see Fig. 2), which can be extrapolated to the case of the supported Pt particles. Therefore, we suggest that Fe migrates from the support onto low-coordinated Pt sites upon UHV annealing at $600 \mathrm{~K}$ and thus modifies $\mathrm{CO}$ adsorption properties in a similar way as carbon.

\section{Conclusions.}

Comparative STM, AES and CO TPD study of $\mathrm{Pt} / \mathrm{Fe}_{3} \mathrm{O}_{4}(111)$, perfect $\mathrm{Pt}(111)$ and highly stepped $\operatorname{Pt}(111)$ surfaces showed that the Pt nanoparticles annealed at $600 \mathrm{~K}$ exhibit a new desorption state at $\sim 270 \mathrm{~K}$. This state is assigned to initial stages of strong metal-support interaction resulting in $\mathrm{Fe}$ migration onto the $\mathrm{Pt}$ particles, although $\mathrm{Fe}$ diffusion into the particles at these temperatures cannot be excluded. 
Both on $\mathrm{Pt} / \mathrm{Fe}_{3} \mathrm{O}_{4}(111)$ and stepped $\mathrm{Pt}(111)$ surfaces $\mathrm{CO}$ is found to dissociate at 500 $\mathrm{K}$ resulting in deposition of carbon, supporting the previous literature results on the key role of low-coordinated sites in $\mathrm{CO}$ dissociation on Pt. The results also suggest that carbon accumulation occurs on the low-coordinated Pt sites. Carbon deposits can be removed by mild oxidation at $500 \mathrm{~K}$.

\section{Acknowledgements.}

We thank the Fonds der Chemischen Industrie for financial support. 


\section{References.}

[1] R. Imbihl and G. Ertl, Chem. Rev. 95 (1995) 697.

[2] R. W. McCabe and L. D. Schmidt, Surf. Sci. 66 (1977) 101.

[3] G. Ertl, M. Neumann, and K. M. Streit, Surf. Sci. 64 (1977) 393.

[4] H. Steininger, S. Lehwald, and H. Ibach, Surf. Sci. 123 (1982) 264.

[5] D. M. Collins and W. E. Spicer, Surf. Sci. 69 (1977) 85.

[6] H. Hopster and H. Ibach, Surf. Sci. 77 (1978) 109.

[7] B. E. Hayden, K. Kretzschmar, A. M. Bradshaw, and R. G. Greenler, Surf. Sci. 149 (1985) 394.

[8] M. R. McClellan, J. L. Gland, and F. R. McFeeley, Surf. Sci. 112 (1981) 63.

[9] E. I. Altman and R. J. Gorte, Surf. Sci. 172 (1986) 71.

[10] E. I. Altman and R. J. Gorte, Surf. Sci. 195 (1988) 392.

[11] D. R. Mullins and K. Z. Zhang, Surf. Sci. 513 (2002) 163.

[12] D. L. Doering, H. Poppa, and J. T. Dickinson, J. Vac. Sci. Tech. 20 (1982) 827.

[13] Y. Iwasawa, R. Mason, M. Textor, and G. A. Somorjai, Chem. Phys. Lett. 44 (1976) 468.

[14] B. Lang, R. W. Joyner, and G. A. Somorjai, Surf. Sci. 30 (1972) 454.

[15] X. Q. D. Li and R. Vanselow, Catal. Lett. 2 (1989) 113.

[16] G. Rupprechter, T. Dellwig, H. Unterhalt, and H. J. Freund, J. Phys. Chem. B 105 (2001) 3797.

[17] K. McCrea, J. S. Parker, P. Chen, and G. Somorjai, Surf. Sci. 494 (2001) 238.

[18] M. A. Vannice and C. C. Twu, J. Catal. 82 (1983) 213.

[19] S. J. Tauster, S. C. Fung, and R. L. Garten, J. Am. Chem. Soc. 100 (1978) 170.

[20] Z. H. Qin, M. Lewandowski, Y. N. Sun, S. Shaikhutdinov, and H. J. Freund, J. Phys. Chem. C 112 (2008) 10209.

[21] Z. H. Qin, M. Lewandowski, Y. N. Sun, S. Shaikhutdinov, and H. J. Freund, J. Phys.: Condens. Matter 21 (2009) 134019.

[22] W. Weiss and W. Ranke, Prog. Surf. Sci. 70 (2002) 1.

[23] W. Weiss and M. Ritter, Phys. Rev. B 59 (1999) 5201.

[24] C. Lemire, R. Meyer, V. E. Henrich, S. Shaikhutdinov, and H. J. Freund, Surf. Sci. 572 (2004) 103.

[25] T. Michely and G. Comsa, Surf. Sci. 256 (1991) 217.

[26] K. H. Hansen, T. Worren, S. Stempel, E. Lægsgaard, M. Bäumer, H. J. Freund, F. Besenbacher, and I. Stensgaard, Phys. Rev. Lett. 83 (1999) 4120.

[27] H. P. Bonzel and R. Ku, J. Chem. Phys. 58 (1973) 4617.

[28] G. Kneringer and F. P. Netzer, Surf. Sci. 49 (1975) 125.

[29] R. W. McCabe and L. D. Schmidt, Surf. Sci. 60 (1976) 85.

[30] R.K. Sharma, W.A. Brown, and D.A. King, Surf. Sci. 414 (1998) 68.

[31] R.B. Shumbera, H.H. Kan, and J.F. Weaver, J. Phys. Chem. C 112 (2008) 4232.

[32] T. Wadayama, H. Osano, T. Maeyama, H. Yoshida, K. Murakami, N. Todoroki, and S. Oda, J. Phys. Chem. C 112 (2008) 8944.

[33] C. Pint, G. Bozzolo, and J. E. Garcés, Surf. Sci. 602 (2008) 559.

[34] A. Ali, M. Abon, P. Beccat, J.C. Bertolini, and B. Tardy, Surf. Sci. 302 (1994) 121.

[35] C. Xu, and B. E. Koel, Surf. Sci. Lett 304 (1994) L505.

[36] B. Vermag, M. Juel, and S. Raaen, Phys. Rev. B. 73 (2006) 033407. 
[37] P. A. Redhead, Vacuum 12 (1962) 203.

[38] S. Shaikhutdinov, M. Heemeier, J. Hoffmann, I. Meusel, B. Richter, M. Bäumer, H. Kuhlenbeck, J. Libuda, H. J. Freund, R. Oldman, S. D. Jackson, C. Konvicka, M. Schmid, and P. Varga, Surf. Sci. 501 (2002) 270.

[39] S. Schauermann, J. Hoffmann, V. Johanek, J. Hartmann, and J. Libuda, Phys. Chem. Chem. Phys. 4 (2002) 3909. 

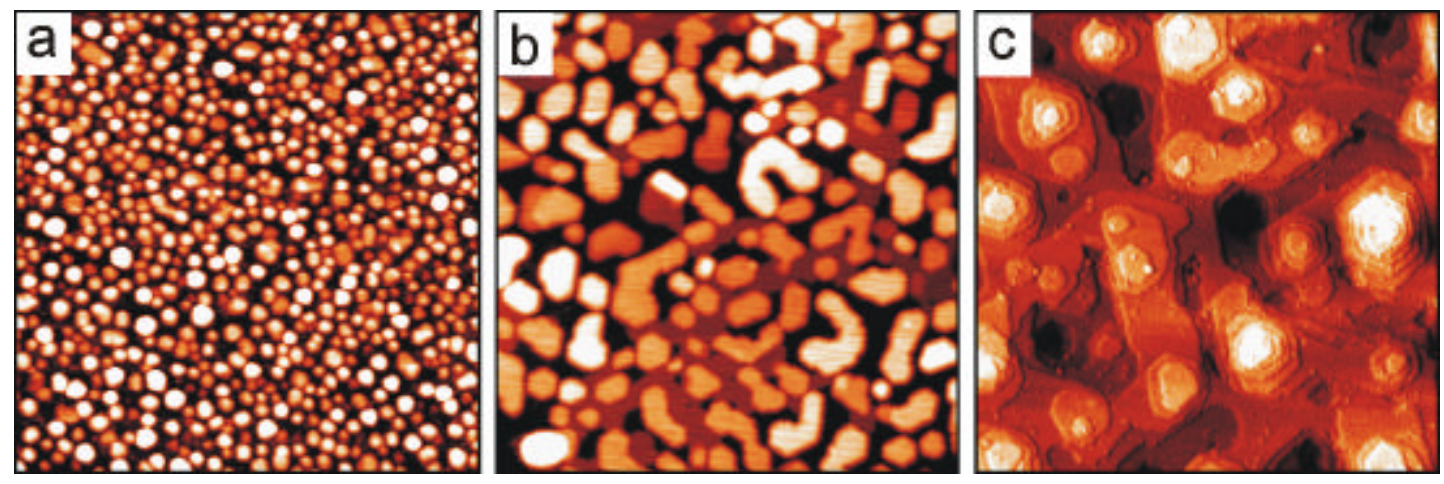

Fig. 1. STM images of the $\mathrm{Pt} / \mathrm{Fe}_{3} \mathrm{O}_{4}(111)$ surface annealed to $600 \mathrm{~K}$ in UHV for $5 \mathrm{~min}$ at 0.8 ML Pt (a) and 2.6 ML (b) Pt coverages. Image (c), presented in differentiated contrast, shows a Pt(111) single crystal surface sputtered by $1 \mathrm{keV} \mathrm{Ar}^{+}$ions at $300 \mathrm{~K}$ and the nannealed to 600 $\mathrm{K}$ for $5 \mathrm{~min}$. Image size is $100 \mathrm{~nm} \times 100 \mathrm{~nm}$; tunneling bias and current are $\mathrm{V}_{\mathrm{S}}=1.4 \mathrm{~V}, \mathrm{I}=1$ nA (a); $1.4 \mathrm{~V}, 0.7 \mathrm{nA}(\mathrm{b}) ; 0.7 \mathrm{~V}, 0.4 \mathrm{nA}$ (c). 

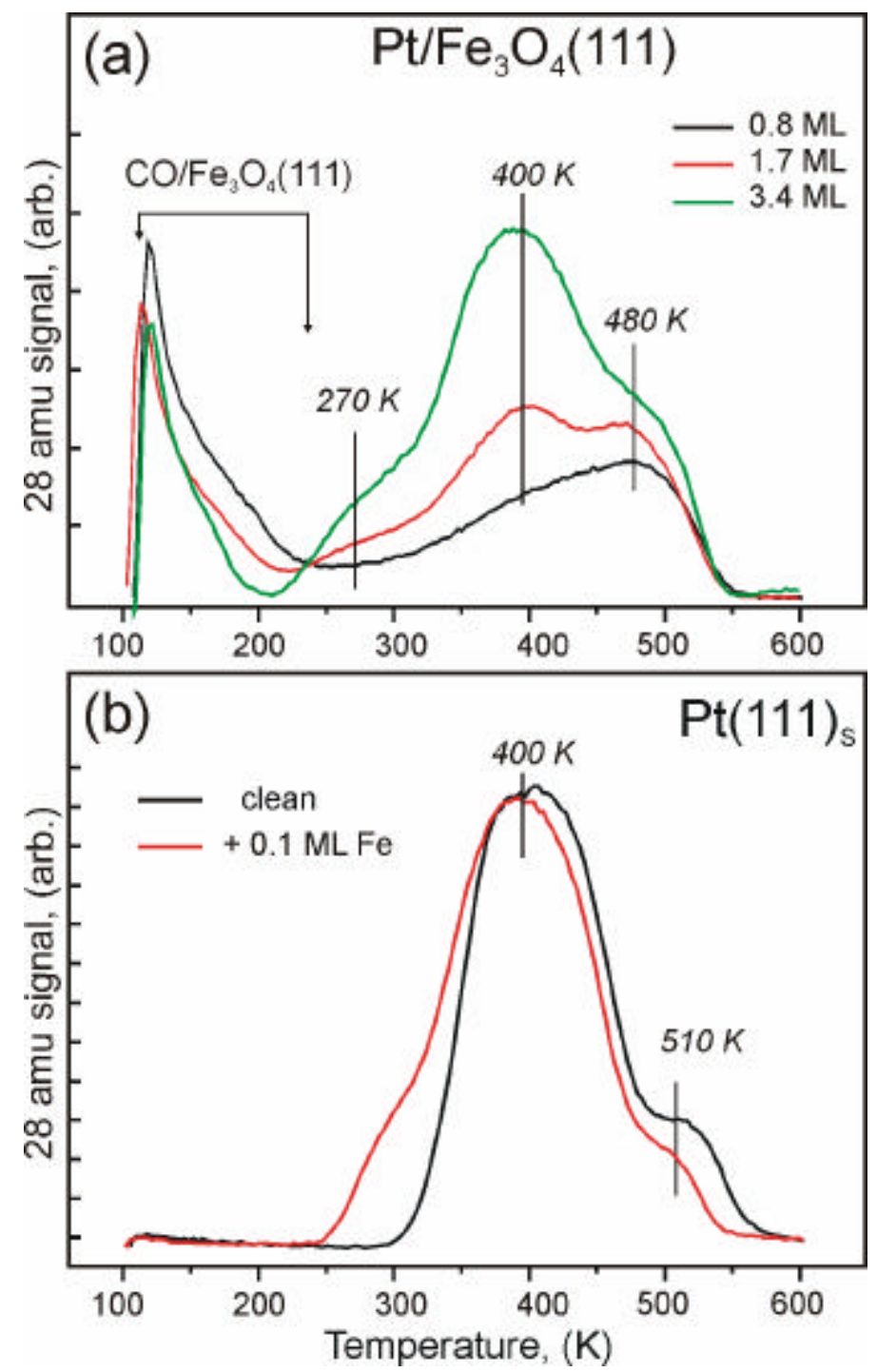

Fig. 2. (a) TPD spectra of $\mathrm{CO}$ on $\mathrm{Pt} / \mathrm{Fe}_{3} \mathrm{O}_{4}(111)$ annealed at $600 \mathrm{~K}$ for $5 \mathrm{~min}$ as a function of Pt coverage as indicated. (b) TPD spectra of CO on the stepped $\mathrm{Pt}(111)$ surface prepared by 1 $\mathrm{keV} \mathrm{Ar}{ }^{+}$sputtering at $300 \mathrm{~K}$ and annealing at $600 \mathrm{~K}$ for $5 \mathrm{~min}$. Subsequently, $0.1 \mathrm{ML}$ of $\mathrm{Fe}$ were deposited onto $\mathrm{Pt}(111)_{\mathrm{S}}$ surface and annealed for $5 \mathrm{~min}$ at $600 \mathrm{~K}$ prior $\mathrm{CO}$ adsorption. $7.5 \mathrm{~L}$ of $\mathrm{CO}$ were dosed at $100 \mathrm{~K}$ in each case. The heating rate is $3 \mathrm{~K} / \mathrm{sec}$. 


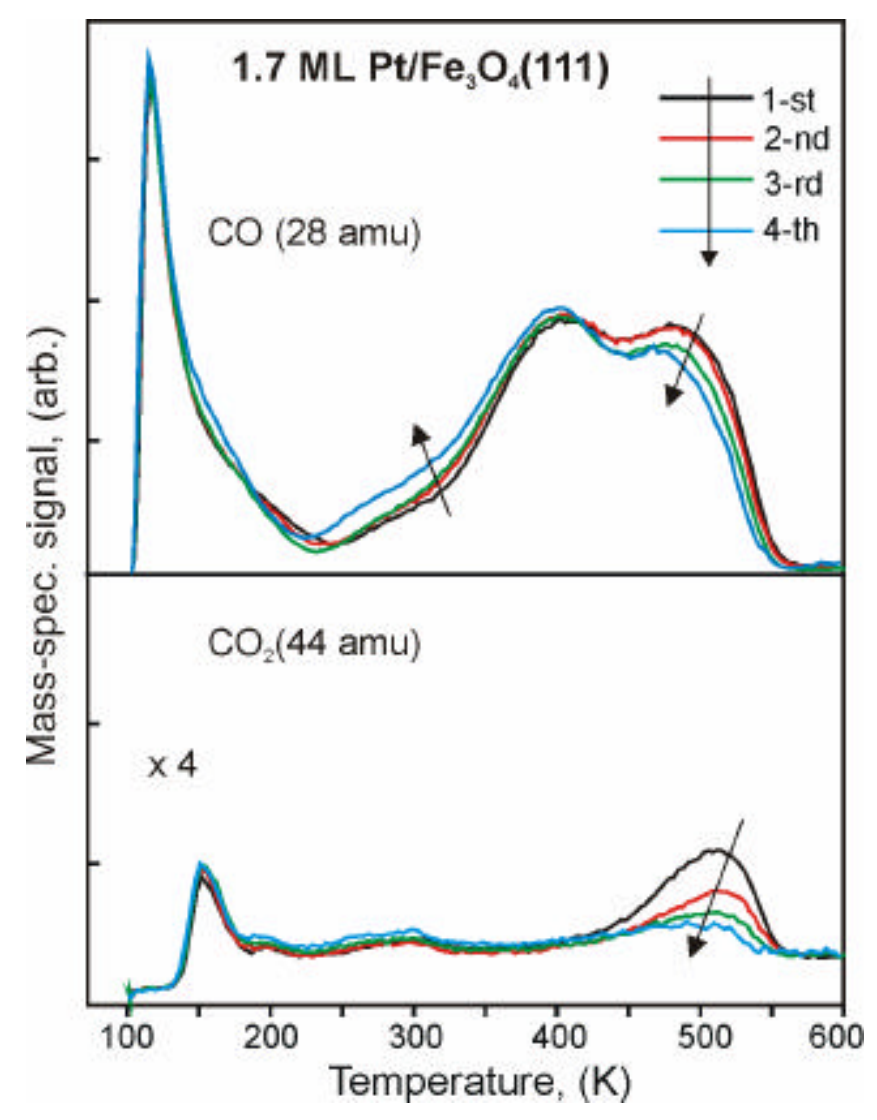

Fig. 3. Repeated TPD spectra of 7.5 L CO adsorbed at $100 \mathrm{~K}$ on $1.7 \mathrm{ML} \mathrm{Pt/Fe}{ }_{3} \mathrm{O}_{4}(111)$. The $28(\mathrm{CO})$ and $44\left(\mathrm{CO}_{2}\right)$ amu signals are shown. The heating rate is $3 \mathrm{~K} / \mathrm{sec}$. 

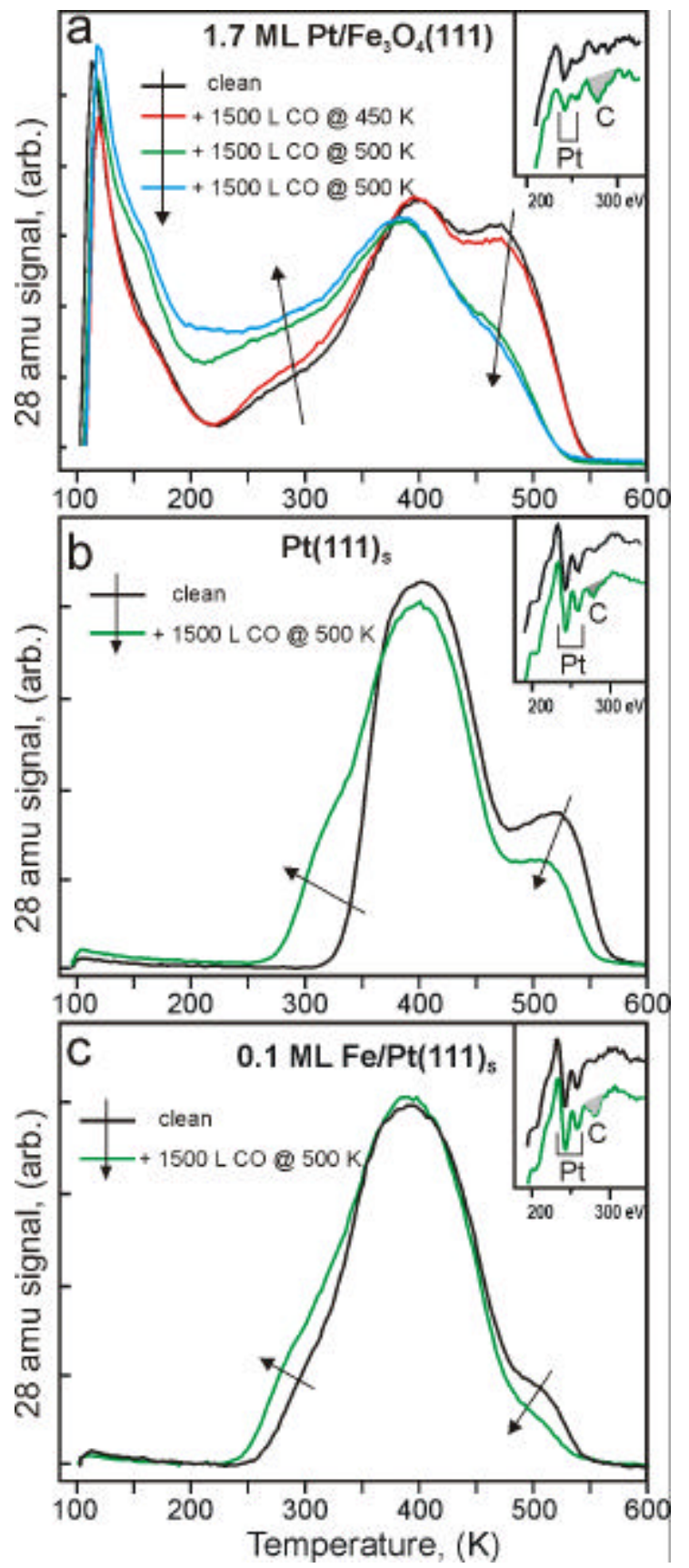

Fig. 4. TPD spectra of $\mathrm{CO}$ on (a) $\mathrm{Pt} / \mathrm{Fe}_{3} \mathrm{O}_{4}(111)$, (b) stepped $\mathrm{Pt}(111)_{\mathrm{s}}$, and (c) $0.1 \mathrm{ML}$ $\mathrm{Fe} / \mathrm{Pt}(111)_{\mathrm{S}}$ surfaces after high $\mathrm{CO}$ exposures as indicated. The heating rate is $3 \mathrm{~K} / \mathrm{sec}$. The insets show corresponding AES spectra (in the same color code). Formation of carbon upon exposure at $500 \mathrm{~K}$ is observed. 

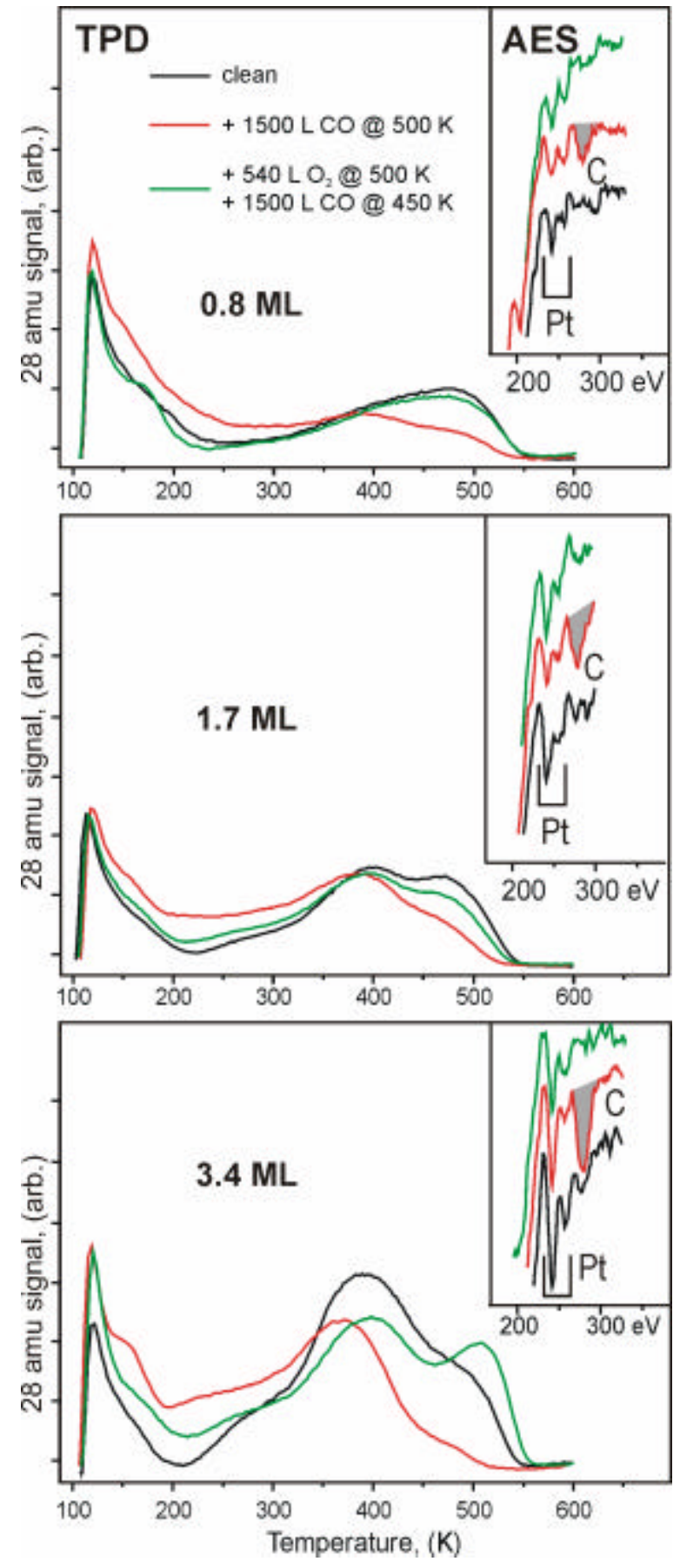

Fig. 5. TPD spectra of $\mathrm{CO}$ on $\mathrm{Pt} / \mathrm{Fe}_{3} \mathrm{O}_{4}(111)$ annealed at $600 \mathrm{~K}$ for 5 min as a function of $\mathrm{Pt}$ coverage as indicated. Then each sample was treated with $1500 \mathrm{~L}$ of $\mathrm{CO}$ at $500 \mathrm{~K}$. Subsequently, the sample was exposed to $540 \mathrm{~L} \mathrm{O}_{2}$ at $500 \mathrm{~K}$ and $1500 \mathrm{~L} \mathrm{CO}$ at $450 \mathrm{~K}$. $7.5 \mathrm{~L}$ of $\mathrm{CO}$ were dosed at $100 \mathrm{~K}$ in each case. Heating rate is $3 \mathrm{~K} / \mathrm{sec}$. The corresponding AES spectra are shown in the insets in the same color code. 